\title{
THE SEISMIC PERFORMANCE RELIABILITY OF REINFORCED CONCRETE MOMENT STRUCTURES
}

\author{
Hossein Shahraki, Naser Shabakhty
}

Original scientific pape In this paper, seismic performance reliability of reinforced concrete (RC) structures was evaluated based on response surface method using a systemic approach. In the systemic approach, limit state functions were applied at the structural component level and structure performance reliability index was calculated with a systemic approach through series and parallel combinations of structural components. The limit state functions were estimated through improved response surface method based on block sampling design of random variables. Numerical studies showed that the proposed systemic approach could calculate performance reliability indices at different damage levels from structural components while only one reliability index was evaluated through the overall approach for the given performance levels. The results indicated that performance reliability indices increased when the nonperformance scenarios were examined for high levels of components damage, and performance reliability indices of the overall approach corresponded to an interval including levels 2 and 3 of the systemic approach.

Keywords: performance; reliability; response surface method; systemic approach

Seizmička pouzdanost konstrukcija od armiranog betona

Izvorni znanstveni članak

U ovom se radu procjenjuje pouzdanost seizmičkih karakteristika konstrukcija od armiranog betona (RC) na temelju response surface metode primjenom sustavnog pristupa. U sistemskom pristupu primijenjene su funkcije graničnog stanja na razini konstrukcijske komponente i izračunat je indeks pouzdanosti performanse konstrukcije sustavnim pristupom putem serijskih i paralelnih kombinacija konstrukcijskih komponenti. Proračunate su funkcije graničnog stanja poboljšanom metodom odziva površine na temelju slučajnih varijabli konstrukcije uzorka bloka. Numerička su proučavanja pokazala da se predloženim sustavnim pristupom mogu dobiti pokazatelji pouzdanosti performansi na različitim razinama oštećenja konstrukcijskih komponenti dok je samo jedan pokazatelj pouzdanosti procijenjen općim pristupom za zadane razine performansi. Rezultati su pokazali da su pokazatelji pouzdanosti performansi porasli kada su se ispitivali scenariji bez performance za visoke razine oštećenja komponenti, i pokazatelji pouzdanosti performansi kod općeg pristupa odgovarali su intervalu uključujući razine 2 i 3 sustavnog pristupa.

Ključne riječi: performansa; pouzdanost; response surface metoda; sistemski pristup

\section{Introduction}

Earthquake is a natural hazard that has inflicted irrecoverable losses on human societies and civil structures. To deal with this natural hazard and mitigate its losses, assessment of structural performance against earthquakes is one of the most interesting issues in recent years. Since the ground motion intensity, material properties and external loads are uncertain, so a comprehensive assessment of the seismic performance reliability of RC structures is essential.

Monte Carlo Simulations (MCS) is a technique to incorporate uncertainties in the seismic performance assessment of RC structures. Although the results of this technique are accurate but for real structures will require significant computational efforts. To overcome this problem, Response Surface Method (RSM) has been proposed. In RSM, an explicit approximation is formed for implicit Limit State Function (LSF) through some deterministic structural analyses to calculate reliability of structure using First Order Reliability Method (FORM), or Second Order Reliability Method (SORM). In [1] the authors considered a second order polynomial Response Surface Function (RSF) without interaction terms, and sensitivity of failure probability for selecting of experimental points was studied. It was shown that selection of experimental points affects RSF approximation and corresponding failure probability significantly [1]. Application of higher order polynomials to approximate LSF was indicated in [2]. A non-constant order polynomial was used for LSF and order of this polynomial was determined with statistical analysis of coefficients. It should be noted that this technique may lead to an ill-conditioned systems of equations. Kang et al. [3] proposed an improved response surface using moving least squares approximation which considered higher weights for the experimental points close to design point. First and second order RSFs were employed to evaluate the seismic fragility of reinforced concrete structures in [4]. It was indicated that these RSFs are sensitive to sampling design, and results of second order RSF are more accurate than first order RSF [4]. Zhao and Qiu [5] proposed a RSM using control points which can guarantee that experimental point lies exactly on the failure surface and is close to the actual design point. Application of RSM for the evaluation of the response statistics of structural systems subjected to stochastic excitation was indicated in [6].

A probabilistic framework was proposed to relate ground motion intensities to structural responses in [7]. In this method, the displacement capacity and transition point of structure are calculated based on a set of ground motion records. The output of this technique is a curve which indicates cumulative probability of structural collapse in terms of ground motion intensities. These curves were calculated for a RC building by incorporating uncertainties in ground motions by Faggella et al. [8].

Presently it has not been well investigated that computation of seismic performance reliability of a $\mathrm{RC}$ structure requires knowing what constituents of the structure are being in a failed or satisfactory performance. Such knowledge is essential for estimating the 
performance reliability of a RC structure and imposes a systemic methodology for this purpose. In this study, an integrated algorithm is proposed to calculate seismic performance reliability of RC structures which can model uncertainties at structural elements level and also calculate the seismic performance reliability of the structural system for different damage levels of components. This algorithm is based on an improved RSM, FORM, conditional reliability indices and linear safety margins of structural components.

\section{Improved RSM to estimate LSF}

In seismic reliability studies, LSF shows the boundary between safety and failure domains. In most cases, LSF cannot be explicitly formulated in terms of random variables, particularly for real structures including large number of random variables. An effective technique which can be used for such problems is RSM, in which implicit LSF is approximated by an explicit expression as:

$$
G(\boldsymbol{X}) \approx R P(\boldsymbol{C} ; \boldsymbol{X})
$$

where $\boldsymbol{X}$ is vector of random variables, $G$ is implicit LSF, $R P$ is estimated RSF and $\mathrm{C}$ is a vector of RSF parameters which calculated based on deterministic structural responses at experimental points. RSF has been widely used as polynomials in structural random analysis problems and two factors are effective in accuracy of the results: polynomial order and selection of experimental points $[9,10]$. Polynomial order is selected such that there is a compromise between accuracy and efficiency of calculation. It is evident that the use of high-order polynomials improves accuracy, but increases computational efforts. In terms of efficiency, polynomial order should be selected as the number of deterministic structural analyses is reduced for calculation of RSF parameters, which is important in problems with many random variables. In addition, it may be led to an illcondition system of equations when using high-order polynomials [2]. Accordingly, a second-order polynomial with interaction terms was applied in this study:

$$
\begin{aligned}
R P(\boldsymbol{X}) & =c_{0}+\sum_{i=1}^{N} c_{i} x_{i}+\sum_{i=1}^{N} c_{i i} x_{i}^{2}+ \\
& +\sum_{i=1}^{N-1} \sum_{j=i+1}^{N} c_{i j} x_{i} x_{j}
\end{aligned}
$$

where $c_{0}, \mathrm{c}_{i}, \mathrm{c}_{i i}$ and $\mathrm{c}_{i j}$ are polynomial coefficients with the number of $1+2 N+N(N-1) / 2$ and $x_{i} ; i=1, \ldots, N$ are random variables. Coefficients of this RSF are calculated based on a set of experimental points on the exact LSF. It is important to select experimental points for estimating LSF properly. For this reason, an improved algorithm is repeatedly applied for fitting RSF as given in Fig. 1. In the first iteration of this algorithm, experimental points with the number of $10 \times[1+2 N+N(N-1) / 2)]$ are generated around mean of random variables. Response parameters of structure are calculated at these points with Non-Linear Dynamic Analysis (NLDA); then, RSF is fitted as Eq. (2). Reliability index $(\beta)$, design point (DP) and relative importance of random variables are calculated for the fitted RSF through FORM. $\beta$ is Hasofer-Lind reliability index [11] and relative importance of random variables is identified using importance measures of FORM in [12].



Figure1 Flowchart of the proposed algorithm for fitting LSF and calculating performance reliability indexes
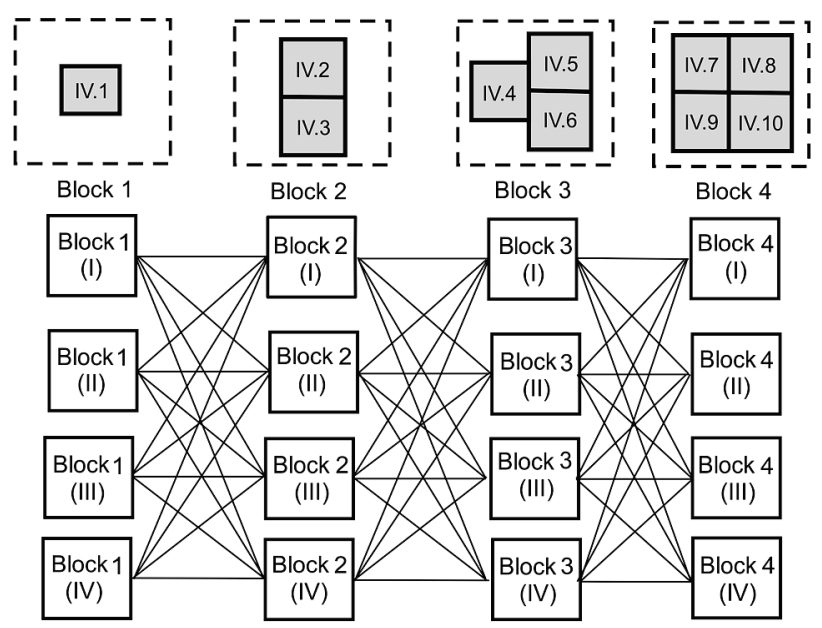

Figure 2 The blocksampling design based on relative importance of random variables

Sampling blocks are considered based on relative importance of random variables so that the most important variable is in the first block, two variables are in the second block (with importance ranking 2 and 3), three variables are in the third block (with importance ranking 4, 5 and 6) and so on. New experimental points are generated in these sampling blocks for the next 
iterations of this algorithm. The experimental points are ordered in each block with 4 states: i) minimum to maximum, ii) maximum to minimum, iii) maximum in the median with a descending order on two sides, and iv) minimum in the median with an ascending order on two sides. The total number of deterministic analyses in every iteration is $4^{\mathrm{NB}} \times \mathrm{NV}$ where $\mathrm{NB}$ and $\mathrm{NV}$ are the number of sampling blocks and the number of random variables, respectively. The sampling design for 10 random variables is shown in Fig. 2, in which the number after IV indicates the ranking of the random variable for importance. This sampling design considers more experimental points for the important random variables; therefore, LSF can be estimated more properly. In the next iterations of this algorithm, point of the sampling center is improved based on a linear interpolation strategy [13] as:

$$
\begin{aligned}
& \text { If } G\left(D P_{j}\right) \geq G\left(C P_{j}\right) \\
& C P_{j+1}=C P_{j}+\left(D P_{j}-C P_{j}\right) \frac{G\left(C P_{j}\right)}{G\left(C P_{j}\right)-G\left(D P_{j}\right)} \\
& \text { If } G\left(D P_{j}\right)<G\left(C P_{j}\right) \\
& C P_{j+1}=D P_{j}+\left(C P_{j}-D P_{j}\right) \frac{G\left(D P_{j}\right)}{G\left(D P_{j}\right)-G\left(C P_{j}\right)}
\end{aligned}
$$

where $C P_{j}$ and $D P_{j}$ are coordinates of sampling center point and design point in iteration $j, g\left(C P_{j}\right)$ and $g\left(D P_{j}\right)$ are structural responses based on nonlinear dynamical analysis in $C P_{j}$ and $D P_{j}$, respectively, and $C P_{j+1}$ is new coordinates of sampling center point. This iterative algorithm will continue until the predefined tolerance criteria are satisfied as: $\left(C P_{j+1}-C P_{j}\right) / C P_{j} \leq$ $|0,05|$ and $\left(D P_{j}-D P_{j-1}\right) / D P_{j-1} \leq|0,01|$.

Quality and accuracy of RSF are checked with a descriptive statistical measure, $R_{a d j}^{2}$, which indicates correlation between the estimated and exact values of LSF [14]:

$$
\begin{aligned}
& R_{a d j}^{2}=R^{2}-\frac{v-1}{o-v}\left(1-R^{2}\right) \\
& R^{2}=\frac{\sum_{k=1}^{o}\left[G\left(X^{(k)}\right)\right]^{2}-\sum_{k=1}^{o}\left[G\left(X^{(k)}\right)-R P\left(C ; X^{(k)}\right)\right]^{2}}{\sum_{k=1}^{o}\left[G\left(X^{(k)}\right)\right]^{2}}
\end{aligned}
$$

where $o$ is the number of experimental points and $v$ is the number of RSF parameters. This criterion was used as $R_{a d j}^{2} \geq 0,95$ in this study.

\section{The proposed systemic approach}

Uncertainties in a $\mathrm{RC}$ structure are related to uncertainties in constituents of that structure; for example, uncertainty of concrete compressive strength in a RC structure is caused by its local variability at structural components level. This local variability causes reliability indices to be different for a given performance level in different structural components. Consequently, application of a systemic approach is necessary for evaluation of seismic performance reliability in these structures. In this study, a systemic approach is proposed which is quite general in concept, so that it can be used for calculating performance reliability of RC structures at different damage levels of structural components. In this approach, LSF was defined at structural component level, as Eq. (2), and probability of exceeding a performance level was determined for each structural component as:

$$
\begin{aligned}
P_{n s p-i}= & P\left(G_{i}(X) \leq 0\right)=P\left(G_{i}\left(\bar{T}^{-1}(\bar{Z})\right) \leq 0\right)= \\
& =P\left(g_{i}(\overline{\mathrm{Z}}) \leq 0\right)
\end{aligned}
$$

with $\bar{Z}=\bar{T}(X)$, basic variables of $X=\left(x_{1}, x_{2}, \ldots, x_{n}\right)$ were transformed into standard normal variables of $\bar{Z}=\left(z_{1}, z_{2}, \ldots, z_{n}\right)$. As demonstrated in Fig. 3, $g_{i}$ can be linearized at a point with distance $\beta$ from origin of coordinates, called design point, and finally $P_{n s p-i}$ can be estimated using the following relation:

$P_{n s p-i}=P\left(g_{i}(\bar{Z}) \leq 0\right) \approx P\left(\bar{\alpha}_{i}^{T} \bar{Z}+\beta_{i} \leq 0\right)=\Phi\left(-\beta_{i}\right)$

where $\bar{\alpha}_{i}=\left(\alpha_{1}^{i}, \alpha_{2}^{i}, \ldots, \alpha_{n}^{i}\right)$ is a vector including directional cosines of linearized LSF, $\beta_{i}$ is reliability index, and $\Phi$ is standard normal cumulative distribution function. It can be said that

$M_{i}=\alpha_{1}^{i} z_{1}+\alpha_{2}^{i} z_{2}+\cdots+\alpha_{n}^{i} z_{\mathrm{n}}+\beta_{i}$

is a linear safety margin for structural component $i$.

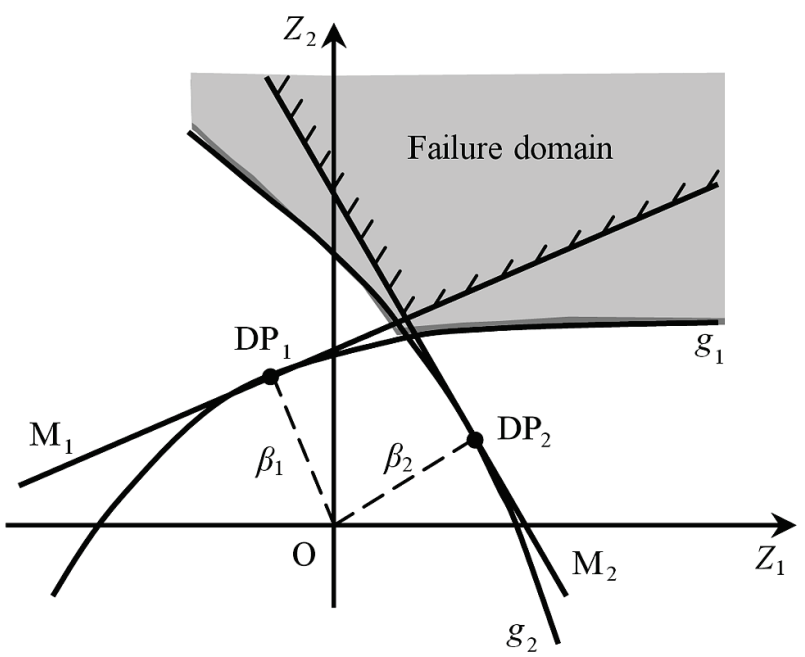

Figure 3 Reliability analysis for two structural elements with linear safety margins

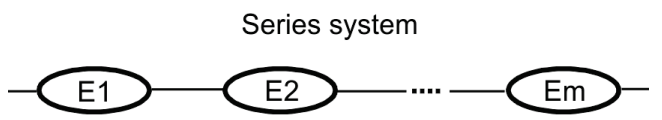

Parallel system



Figure 4 Series and parallel systems of structural elements

To estimate performance reliability in the structure, structural components can be modeled as a series, parallel or combined systems (as shown in Fig. 4). Finally, probability of exceeding performance level can be calculated as [15]: 


$$
\begin{gathered}
P_{n s p}^{S}=P\left(\bigcup_{i=1}^{m}\left(G_{i}(X) \leq 0\right)\right)=P\left(\bigcup_{i=1}^{m}\left(g_{i}(\bar{Z}) \leq 0\right)\right) \approx \\
\approx P\left(\bigcup_{i=1}^{m}\left(\bar{\alpha}_{i}^{T} \bar{Z}+\beta_{i} \leq 0\right)\right)= \\
=1-P\left(\bigcap_{i=1}^{m}\left(\bar{\alpha}_{i}^{T} \bar{Z} \leq \beta_{i}\right)\right)=1-\Phi_{m}(\bar{\beta} ; \overline{\bar{\rho}}) \\
P_{n s p}^{P}=P\left(\bigcap_{i=1}^{m}\left(G_{i}(X) \leq 0\right)\right)=P\left(\bigcap_{i=1}^{m}\left(g_{i}(\bar{Z}) \leq 0\right)\right) \approx \\
=P\left(\bigcap_{i=1}^{m}\left(\bar{\alpha}_{i}^{T} \bar{Z} \leq-\beta_{i}\right)\right)=\Phi_{m}(-\bar{\beta} ; \overline{\bar{\rho}})
\end{gathered}
$$

where $\bar{\beta}=\left(\beta_{1}, \ldots, \beta_{m}\right), \overline{\bar{\rho}}=\left[\rho_{i j}\right]$ is matrix of correlation coefficients between structural components, and $\Phi_{m}$ is the multi-normal distribution function.

It is evident that different scenarios of damage at structural component levels can be applied for evaluating seismic performance reliability of a RC structure and each performance scenario has a unique reliability index. In this study, the most probable performance scenario, which had the smallest reliability index for a given performance level, was used. This scenario was applied at different damage levels of structural components so that performance reliability index of the structural system was calculated at level 0 based on the most critical structural component as:

$\beta_{\text {sys }}^{0}=\begin{gathered}\min \beta_{i}^{0} \\ i=1, \ldots, m\end{gathered}$

At level 0, structural components were separately considered from other components; therefore, their correlation was ignored in the analysis. It is evident that this estimation is very optimistic for performance reliability of structural system.

At level 1, performance reliability index of the structure was estimated through a series system of structural components, as shown in Fig. 5. Because it was not possible to calculate the multi-normal distribution function in Eq. (9) for a large number of components, $P_{n s p}^{S}$ can be estimated using some components of this series system [16]. These components were selected so that their reliability index was within interval $\left[\beta_{\text {min }}^{0}, \beta_{\text {min }}^{0}+\Delta \beta_{1}\right]$, where $\Delta \beta_{1}$ is a defined positive value.

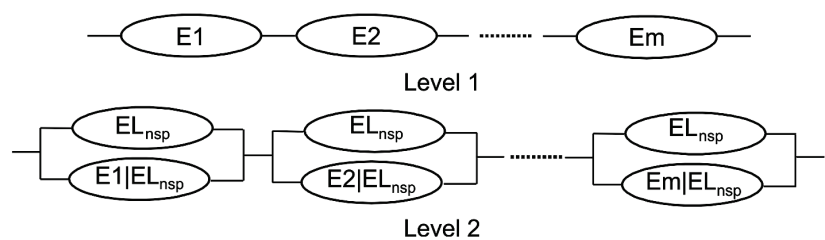

Figure5 Modeling of the performance reliability of structural system at level 1 and level 2

Performance reliability of the structural system at level 2 was calculated based on a combined system, as shown in Fig. 5. It was a series system of parallel subsystems including two structural components. At level 2 , it was assumed that structural component of $\mathrm{L}$ with the smallest reliability index overpassed the given performance level. Then, new conditional reliability indices were calculated for all components (except for component $\mathrm{L}$ ), and $\beta_{\text {min }}^{1}$ was determined. Structural components with conditional reliability indexes within interval $\left[\beta_{\text {min }}^{1}, \beta_{\text {min }}^{1}+\Delta \beta_{2}\right]$ were combined in parallel with component $\mathrm{L}$, where $\Delta \beta_{2}$ is a defined positive value. Finally, performance reliability index of structural system at level 2 was calculated as follows:

i) Conditional safety margins $\left(\mathrm{M}_{\mathrm{Ei} \mid \mathrm{EL}_{\mathrm{nsp}}}\right)$ were evaluated for structural components within interval $\left[\beta_{\min }^{1}, \beta_{\min }^{1}+\Delta \beta_{2}\right]$.

ii) Probability of exceeding the given performance level was calculated for each parallel subsystem using Eq. (10) and the equivalent linear safety margin $\left(\mathrm{M}^{\mathrm{p}}\right)$ were also estimated.

iii) Probability of exceeding the given performance level was calculated for the structure at level 2 by Eq. (9).

It is appropriate to note that $\mathrm{M}_{\mathrm{Ei} \mid \mathrm{EL} \mathrm{L}_{n p}}$ and $\mathrm{M}^{\mathrm{p}}$ are calculated so that the equivalent reliability index $\left(\beta^{\mathrm{e}}\right)$ is equal to $\beta_{\mathrm{Ei} \mid \mathrm{EL} \mathrm{nsp}}$ and $\beta^{P}$, respectively. As a result, they will have identical sensitivity to variations of basic variables [17]. These equivalent linear safety margins $\left(M^{e}\right)$ were estimated as follows:

$M^{e}=\alpha_{1}^{e} z_{1}+\cdots+\alpha_{k}^{e} z_{n}+\beta^{e}=\sum_{j=1}^{n} \alpha_{j}^{e} z_{j}+\beta^{e}$

where $\alpha^{\mathrm{e}}=\left(\alpha_{1}^{\mathrm{e}}, \ldots, \alpha_{n}^{\mathrm{e}}\right)$ is a unit vector calculated using numerical derivative for a negligible increase of $\bar{\varepsilon}$ in basic variables:

$\alpha_{o}^{e}=\frac{\left.\frac{\partial \beta^{P}}{\partial \varepsilon_{o}}\right|_{\bar{\varepsilon}=\overline{0}}}{\sqrt{\sum_{j=1}^{n}\left[\left.\frac{\partial \beta^{P}}{\partial \varepsilon_{j}}\right|_{\bar{\varepsilon}=\overline{0}}\right]^{2}}}$ or $\frac{\left.\frac{\partial \beta_{E i \mid E L_{n s p}}}{\partial \varepsilon_{o}}\right|_{\bar{\varepsilon}=\overline{0}}}{\sqrt{\sum_{j=1}^{n}\left[\left.\frac{\partial \beta_{E i \mid E L_{n s p}}}{\partial \varepsilon_{j}}\right|_{\bar{\varepsilon}=\overline{0}}\right]^{2}}} ;$

$o=1, \ldots, n$

The proposed algorithm could be applied in systemic approach for calculating performance reliability of a structure at different damage levels of the structural components through the following steps:

1) Assume that $m$ is the number of structural components.

2) Define LSF for each structural component.

3) Calculate $\beta_{i}^{0}$ and $P_{n s p-i}(i=1, \ldots, m)$ for the structural components using the algorithm shown in Fig. 1.

4) Evaluate $M_{i}$ for structural components as Eq. (8).

5) Sort structural components based on $\beta_{i}^{0}$ as $\left\{\beta_{E L}^{0}, \beta_{E K}^{0}, \beta_{E 1}^{0}, \beta_{E 2}^{0}, \ldots, \beta_{E Q}^{0}\right\}$ where $\beta_{E L}^{0}$ is $\min \beta_{i}^{0}$, and $\beta_{E Q}^{0}$ is $\max \beta_{i}^{0}$. If two structural components are fully correlated, then, only one of them is selected in this set.

6) Determine level $N$ for analyzing performance reliability of the structure.

7) If $N=0$, then, $\beta_{s y s}^{0}=\beta_{E L}^{0}, P_{n s p}^{0}=P_{n s p-E L}$, and go to Step 19.

8) If $N=1$, then, model the structure as a series system of the components given in Step 5. Consider $\beta_{\text {min }}^{N-1}=\beta_{E L}^{0}$ and go to Step 13 . 
9) If $N>1$, identify critical set $\left\{E_{C / 1}, E_{C / 2}, E_{C / 3}\right.$, $\left.\ldots, E_{C^{\prime} N-1}\right\}$ which includes $N-1$ structural components starting from $\beta_{E L}^{0}$ in $\left\{\beta_{E L}^{0}, \beta_{E K}^{0}\right.$, $\left.\beta_{E 1}^{0}, \beta_{E 2}^{0}, \ldots, \beta_{E Q}^{0}\right\}$.

10) Calculate conditional reliability indices and equivalent linear safety margins $\left(M^{e}\right)$ for the following events from critical set: $\left\{E_{C^{\prime} 2}\left|E_{C^{\prime} 1 \mathrm{nsp}}, E_{C^{\prime} 3}\right| E_{\left(C^{\prime} 1, C^{\prime} 2\right) \mathrm{nsp}}, \ldots\right.$, $\left.E_{C^{\prime} N-1} \mid E_{\left(C^{\prime} 1, C^{\prime} 2, \ldots, C^{\prime} N-2\right) \mathrm{nsp}}\right\}$.

11) Calculate conditional reliability indices $\left(\beta_{i}^{N-1}\right)$ and equivalent conditional safety margins $\left(M^{e}\right)$ for all structural components, except for members of the critical set as:

$$
\begin{aligned}
& \left\{E_{1}\left|E_{\left(C^{\prime} 1, C^{\prime} 2, \ldots, C^{\prime} N-1\right) \mathrm{nsp}}, E_{2}\right| E_{\left(C^{\prime} 1, C^{\prime} 2, \ldots, C^{\prime} N-1\right) \mathrm{nsp}}, \ldots,\right. \\
& \left.E_{m-N+1} \mid E_{\left(C^{\prime} 1, C^{\prime} 2, \ldots, C^{\prime} N-1\right) \mathrm{nsp}}\right\} .
\end{aligned}
$$

12) Consider the smallest reliability index in Step 11 as $\beta_{\min }^{N-1}$.

13) Select $\Delta \beta_{N}$ and consider structural components in interval $\left[\beta_{\min }^{N-1}, \beta_{\min }^{N-1}+\Delta \beta_{N}\right]$; if $N=1$, go to Step 18.

14) Form parallel systems which include $N$ structural components. $N-1$ components of this system were determined in step 10 and the last component is each one of the selected components in Step 13.

15) Calculate probability of $P_{\mathrm{nsp}}^{P}$ and reliability index for each parallel system in Step 14.

16) Determine equivalent linear safety margin $\left(M^{e}\right)$ for each parallel system in Step 14.

17) Form a series system of the parallel systems in Step 14.

18) Calculate $\beta_{\mathrm{sys}}^{N}, P_{\mathrm{nsp}}^{N}$ for the given series system.

19) End.

The proposed approach was applied for a RC structure which was indicated in the following section.

\section{Numerical studies and discussion}

In this section, seismic performance reliability of a $\mathrm{RC}$ structure is evaluated based on systemic approach. In this structure, LSF is defined as:

$G(X)=R P_{L}-R P(X)$

where $R P_{L}$ shows response parameter limit value of $R P(X)$ for performance level. The LSF is defined at components level of structure for performance levels of Immediate Occupancy (IO), Life Safety (LS), and Collapse Prevention (CP) as:

$$
\begin{aligned}
& G_{I O-C E}(X)=R P_{P R C}(0,005 ; 0,1)-R P_{P R C}(X) \\
& G_{L S-C E}(X)=R P_{P R C}(0,015 ; 0,1)-R P_{P R C}(X) \\
& G_{C P-C E}(X)=R P_{P R C}(0,020 ; 0,1)-R P_{P R C}(X) \\
& G_{I O-B E}(X)=R P_{P R B}(0,010 ; 0,1)-R P_{P R B}(X) \\
& G_{L S-B E}(X)=R P_{P R B}(0,020 ; 0,1)-R P_{P R B}(X) \\
& G_{C P-B E}(X)=R P_{P R B}(0,025 ; 0,1)-R P_{P R B}(X)
\end{aligned}
$$

where $R P_{P R C}$ and $R P_{P R B}$ are maximum plastic rotation in column and beam components, respectively. Threshold values of maximum plastic rotation are considered with a lognormal distribution and numbers in parenthesis show mean and coefficient of variations for the given performance levels [18, 19].

Uncertainties relating to ground motion are incorporated in this approach using artificial acceleration records generated by a non-stationary simulation based on the models proposed in $[20,21]$. These accelerograms are scaled in $(0,2 \div 1,5) T$ based on the generated spectral accelerations. In addition, the accelerograms have a significant duration greater than or equal to $10 \mathrm{~s} \mathrm{[22].}$

Uncertainty in properties of materials affects performance of structure because real properties of materials are usually different from those which have been applied in design, which it changes forcedeformation relations for structural members. Therefore, to evaluate performance reliability of the structure, parameters of concrete materials including compressive strength $\left(f_{c}\right)$, strain at compressive strength $\left(\varepsilon_{c 0}\right)$ and ultimate strain $\left(\varepsilon_{c u}\right)$ are considered as random variables. Uncertainties in properties of steel materials are also incorporated through yield strength $\left(F_{s y}\right)$, ultimate strength $\left(F_{s u}\right)$, modulus of elasticity $\left(E_{S}\right)$ and strain at the start of hardening $\left(\varepsilon_{S H}\right)$ of steel bars.

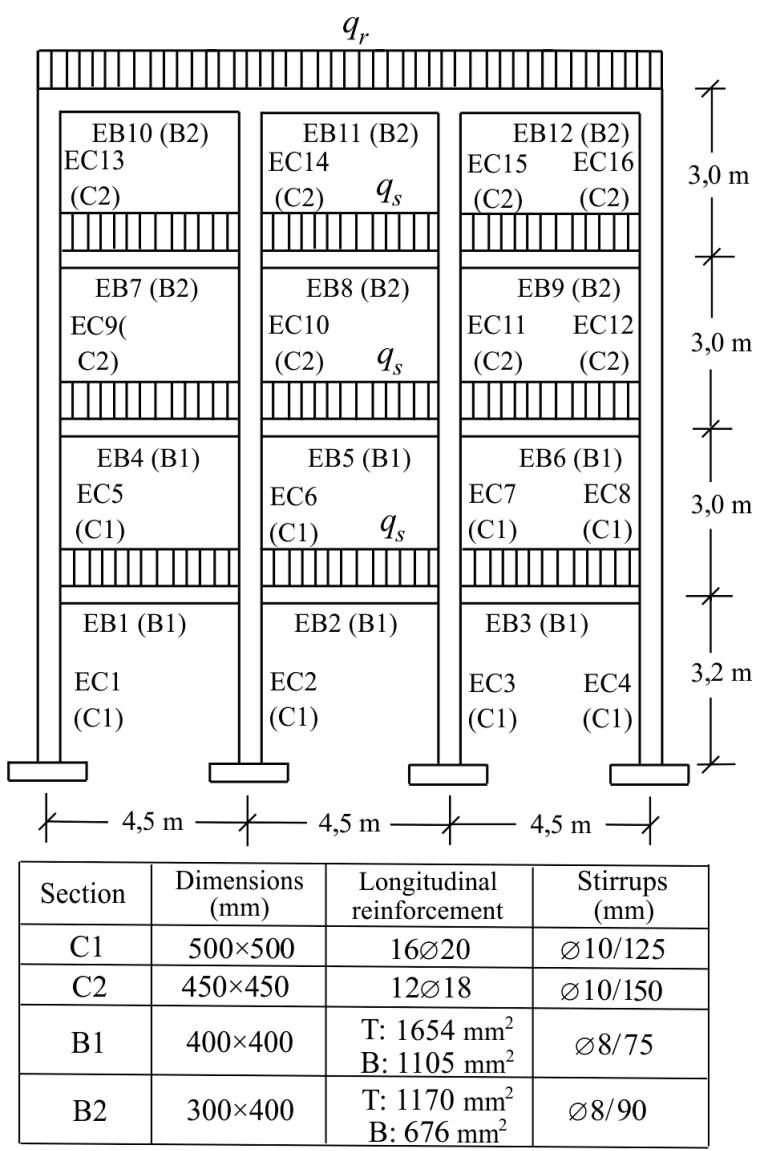

Figure 6 The RC moment frame with 4 stories - 3 bays

Gravitational loads are another source of uncertainty because real construction details can change from those which have been assumed in design. In this study, uncertainty in gravitational loads of roof $\left(q_{r}\right)$ and stories $\left(q_{s}\right)$ were separately considered and their distribution parameters were calculated based on their nominal values in [22] with bias factor $=1,05$ [23]. It is appropriate to note that the RC structure is first subjected to 
gravitational loads, followed by nonlinear dynamic analysis for ground motions. The nonlinear dynamic analysis was carried out using IDARC [24].

The proposed approach was applied for a RC moment frame with three bays and four stories in the city of Kerman which was designed according to [22, 25] (see Fig. 6). Type of probability distribution and distribution parameters are given in Tab. 1 for random variables. Distribution parameters are different at structural components level. Seismic performance reliability indices were calculated for the structural components demonstrated in Fig. 6 based on the LSFs given in
Eqs.(15) to (20) and the results are presented in Fig. 7. It was found that structural components overpassed the given performance levels as EB8, EB7, EC9, EC10, ..., EC1, EC5, EC6, respectively. Therefore, performance reliability indices changed in components of this structure as $\frac{\beta_{I O-E C 6}}{\beta_{I O-E B 8}}=2,54 ; \frac{\beta_{L S-E C 6}}{\beta_{L S-E B 8}}=2,29$ and $\frac{\beta_{C P-E C 6}}{\beta_{C P-E B 8}}=2,21$. EB8 component had the smallest performance reliability index between structural members, accordingly, reliability of this structural system was estimated at level 0 based on this component as $\beta_{I O}^{0}=0,97, \beta_{L S}^{0}=1,30$ and $\beta_{C P}^{0}=$ 1,501 .

Table 1 Parameters of random variables at components level of 4 stories RC frame

\begin{tabular}{|c|c|c|c|c|}
\hline Random variable & Element & Mean & Standard deviation & Distribution type \\
\hline \multirow{4}{*}{$f_{c}(\mathrm{MPa})$} & $\mathrm{EB} 1$ to $\mathrm{EB} 3, \mathrm{EC} 1$ to $\mathrm{EC} 4$ & 32,81 & 4,92 & \multirow{4}{*}{ Lognormal $[26,27]$} \\
\hline & EB4 to EB6, EC5 to EC8 & 29,06 & 4,36 & \\
\hline & EB7 to EB9, EC9 to EC12 & 26,04 & 3,91 & \\
\hline & EB10 to EB12, EC12 to EC16 & 28,10 & 4,21 & \\
\hline \multirow{4}{*}{$\varepsilon_{c 0}$} & EB1 to EB3, EC1 to EC4 & $2,24 \times 10^{-3}$ & $3,37 \times 10^{-4}$ & \multirow{4}{*}{ Lognormal $[26,27]$} \\
\hline & EB4 to EB6, EC5 to EC8 & $2,04 \times 10^{-3}$ & $3,06 \times 10^{-4}$ & \\
\hline & EB7 to EB9, EC9 to EC12 & $1,72 \times 10^{-3}$ & $2,58 \times 10^{-4}$ & \\
\hline & EB10 to EB12, EC12 to EC16 & $1,85 \times 10^{-3}$ & $2,78 \times 10^{-4}$ & \\
\hline \multirow{4}{*}{$\varepsilon_{c u}$} & EB1 to EB3, EC1 to EC4 & $3,78 \times 10^{-3}$ & $5,67 \times 10^{-4}$ & \multirow{4}{*}{ Lognormal $[26,27]$} \\
\hline & EB4 to EB6, EC5 to EC8 & $3,54 \times 10^{-3}$ & $5,31 \times 10^{-4}$ & \\
\hline & EB7 to EB9, EC9 to EC12 & $3,0 \times 10^{-3}$ & $4,5 \times 10^{-4}$ & \\
\hline & EB10 to EB12, EC12 to EC16 & $3,26 \times 10^{-3}$ & $4,89 \times 10^{-4}$ & \\
\hline \multirow{4}{*}{$F_{s y}(\mathrm{MPa})$} & EB1 to EB3, EC1 to EC4 & 308,2 & 15,41 & \multirow{4}{*}{ Lognormal $[26,27]$} \\
\hline & EB4 to EB6, EC5 to EC8 & 297,21 & 14,86 & \\
\hline & EB7 to EB9, EC9 to EC12 & 297,21 & 14,86 & \\
\hline & EB10 to EB12, EC12 to EC16 & 308,2 & 15,41 & \\
\hline \multirow{4}{*}{$F_{s u}(\mathrm{MPa})$} & EB1 to EB3, EC1 to EC4 & 517,1 & 25,85 & \multirow{4}{*}{ Lognormal $[26,27]$} \\
\hline & EB4 to EB6, EC5 to EC8 & 497,1 & 24,86 & \\
\hline & EB7 to EB9, EC9 to EC12 & 497,1 & 24,86 & \\
\hline & EB10 to EB12, EC12 to EC16 & 517,1 & 25,85 & \\
\hline \multirow{4}{*}{$E_{S}(\mathrm{MPa})$} & EB1 to EB3, EC1 to EC4 & 200598,9 & 10029,95 & \multirow{4}{*}{ Lognormal $[26,27]$} \\
\hline & EB4 to EB6, EC5 to EC8 & 198986,7 & 9949,33 & \\
\hline & EB7 to EB9, EC9 to EC12 & 198986,7 & 9949,33 & \\
\hline & EB10 to EB12, EC12 to EC16 & 200598,9 & 10029,95 & \\
\hline \multirow{4}{*}{$\varepsilon_{S H}$} & EB1 to EB3, EC1 to EC4 & $3,21 \times 10^{-2}$ & $3,21 \times 10^{-3}$ & \multirow{4}{*}{ Lognormal $[26,27]$} \\
\hline & EB4 to EB6, EC5 to EC8 & $2,96 \times 10^{-2}$ & $2,96 \times 10^{-3}$ & \\
\hline & EB7 to EB9, EC9 to EC12 & $2,96 \times 10^{-2}$ & $2,96 \times 10^{-3}$ & \\
\hline & EB10 to EB12, EC12 to EC16 & $3,21 \times 10^{-2}$ & $3,21 \times 10^{-3}$ & \\
\hline \multirow{3}{*}{$q_{S}(\mathrm{kN} / \mathrm{m})$} & EB1 to EB3, EC1 to EC4 & 42,14 & 6,32 & \multirow{3}{*}{ Normal $[23,27]$} \\
\hline & EB4 to EB6, EC5 to EC8 & 40,05 & 6,01 & \\
\hline & EB7 to EB9, EC9 to EC12 & 36,22 & 5,43 & \\
\hline$q_{r}(\mathrm{kN} / \mathrm{m})$ & EB10 to EB12, EC12 to EC16 & 33,78 & 5,07 & Normal $[23,27]$ \\
\hline$S_{a}(\mathrm{~g})$ & EB1 to EB12, EC1 to EC16 & 0,69 & 0,48 & Extreme type II [27] \\
\hline
\end{tabular}

Table 2 The performance reliability of 4 stories RC frame with systemic approach

\begin{tabular}{|c|c|c|c|c|c|c|c|}
\hline & P. L. & $\beta_{\min }^{N-1}$ & $\Delta \beta_{N}$ & $\beta_{\text {sys }}^{N}$ & $P_{n s p}^{N}\left(\times 10^{-2}\right)$ & Boole bound $\left(P_{n s p}^{N} \times 10^{-2}\right)$ & KHD bound $\left(P_{n s p}^{N} \times 10^{-2}\right)$ \\
\hline \multirow{3}{*}{ L1 } & $\mathrm{IO}$ & 0,979 & 0,150 & 0,665 & 25,314 & $16,608 \div 60,354$ & $17,266 \div 27,533$ \\
\hline & $\mathrm{LS}$ & 1,380 & 0,353 & 1,343 & 8,966 & $8,379 \div 31,905$ & $8,723 \div 9,258$ \\
\hline & $\mathrm{CP}$ & 1,501 & 0,353 & 1,472 & 7,056 & $6,668 \div 25,981$ & $6,945 \div 7,185$ \\
\hline \multirow{3}{*}{ L2 } & $\mathrm{IO}$ & $-1,002$ & 0,529 & 0,976 & 16,450 & $15,822 \div 59,695$ & $16,369 \div 17,143$ \\
\hline & $\mathrm{LS}$ & $-1,206$ & 1,442 & 1,365 & 8,620 & $8,183 \div 35,335$ & $8,396 \div 8,617$ \\
\hline & $\mathrm{CP}$ & $-1,285$ & 1,468 & 1,484 & 6,89 & $6,549 \div 29,344$ & $6,73 \div 6,893$ \\
\hline \multirow{3}{*}{ L 3} & $\mathrm{IO}$ & 1,021 & 0,245 & 1,622 & 5,250 & $5,242 \div 24,637$ & $5,245 \div 5,251$ \\
\hline & $\mathrm{LS}$ & 1,572 & 0,190 & 2,186 & 1,440 & $1,44 \div 7,159$ & $1,440 \div 1,441$ \\
\hline & $\mathrm{CP}$ & 1,689 & 0,244 & 2,328 & 0,996 & $0,996 \div 4,860$ & $0,996 \div 0,997$ \\
\hline \multirow{3}{*}{ L4 } & $\mathrm{IO}$ & 1,011 & 0,386 & 1,728 & 4,201 & $4,179 \div 19,699$ & $4,201 \div 4,210$ \\
\hline & $\mathrm{LS}$ & 1,754 & 0,237 & 2,255 & 1,207 & $1,131 \div 5,600$ & $1,161 \div 1,235$ \\
\hline & $\mathrm{CP}$ & 1,872 & 0,269 & 2,411 & 0,795 & $0,708 \div 3,605$ & $0,739 \div 0,840$ \\
\hline
\end{tabular}

By applying the proposed algorithm in this structure, performance reliability indices were calculated at levels 1 to 4 and the results are shown in Tab. 2. It should be noted that performance reliability of this structure was 
evaluated at levels 1 to 4 based on the combined systems as:

L1: $\{[\mathrm{EB} 8]-[\mathrm{EB} 7]-[\mathrm{EC} 9]-[\mathrm{EC} 10]\}$,

L2: $\left\{\left[\mathrm{EB} 8_{\text {nsp }} \mathrm{EB} 7 \mid \mathrm{EB} 8_{\text {nsp }}\right]-\left[\mathrm{EB} 8_{\text {nsp }} \mathrm{EC} 9 \mid \mathrm{EB} 8_{\text {nsp }}\right]-\left[\mathrm{EB} 8_{\text {nsp }}\right.\right.$

$\left.\left.\mathrm{EC} 10 \mid \mathrm{EB}_{\text {nsp }}\right]-\left[\mathrm{EB} 8_{\text {nsp }} \mathrm{EC} 14 \mid \mathrm{EB} 8_{\text {nsp }}\right]\right\}$,

L3: $\left\{\left[\mathrm{EB} 8_{\text {nsp }} \mathrm{EB} 7_{\text {nsp }} \mathrm{EC} 9 \mid(\mathrm{EB} 8, \mathrm{~EB} 7)_{\mathrm{nsp}}\right]-\left[\mathrm{EB} 8_{\mathrm{nsp}} \mathrm{EB}_{\text {nsp }}\right.\right.$

$\left.\mathrm{EC} 10 \mid(\mathrm{EB} 8, \mathrm{~EB} 7)_{\mathrm{nsp}}\right]-\left[\mathrm{EB} 8_{\mathrm{nsp}} \mathrm{EB}_{\mathrm{nsp}_{\mathrm{np}}} \mathrm{EC} 14 \mid(\mathrm{EB} 8, \mathrm{~EB} 7)\right.$

$\left.\left.{ }_{\mathrm{nsp}}\right]-\left[\mathrm{EB} 8_{\mathrm{nsp}} \mathrm{EB}_{\mathrm{nsp}} \mathrm{EC} 13 \mid(\mathrm{EB} 8, \mathrm{~EB} 7)_{\mathrm{nsp}}\right]\right\}$,

L4: $\left\{\left[\mathrm{EB} 8_{\mathrm{nsp}} \mathrm{EB} 7_{\mathrm{nsp}} \mathrm{EC}\right.\right.$ nsp $_{\text {EC10| }}$ (EB8, EB7, EC9) $\left.{ }_{\mathrm{nsp}}\right]-$

[EB8 $\left.{ }_{\text {nsp }} \mathrm{EB}_{\mathrm{nsp}_{\mathrm{n}}} \mathrm{EC}_{\mathrm{nsp}} \mathrm{EC} 14 \mid(\mathrm{EB} 8, \mathrm{~EB} 7, \mathrm{EC} 9)_{\mathrm{nsp}}\right]-$

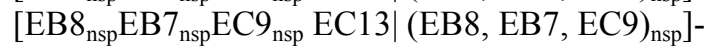

$\left.\left[\mathrm{EB} 8_{\mathrm{nsp}} \mathrm{EB} 7_{\mathrm{nsp}} \mathrm{EC} 9_{\mathrm{nsp}} \mathrm{EB} 4 \mid(\mathrm{EB} 8, \mathrm{~EB} 7, \mathrm{EC} 9)_{\mathrm{nsp}}\right]\right\}$.

Symbols "-" and "[ ]" show that the components are combined as series and parallel systems, respectively. In Tab. 2, it can be observed that probability of exceeding the given performance levels was reduced until analysis level increased, which was considerable for L2 and L3, i.e. EB8 component would overpass the given performance levels which would have a significant effect on performance reliability index of this structure. The results were verified at each analysis level with the Boole bound and KHD bound [28] for each performance level, as shown in Tab. 2. Comparison of the results of the proposed algorithm with these bounds showed that probability of exceeding the given performance levels was properly calculated.

Annual probability of exceeding the given performance levels can be calculated for this structure using a Poisson arrival process for occurrence of earthquake [29] as:

$P_{a n-n s p}=1-\exp \left(-\lambda P_{\mathrm{nsp}}^{N}\right)$

where $\lambda$ is annual rate of earthquake occurrence, which is 0,0039 for the given spectral accelerations [20]. In other words, annual reliability for a performance level can be determined as: $\beta_{a n}=-\Phi^{-1}\left(P_{a n-n s p}\right)$. Annual probability of exceeding the given performance levels along with annual reliability index is shown in Tab. 3 for this structure from levels 0 to 4 . It was recommended a maximum failure probability of $10^{-4}$ in $[30,31]$ based on a reference period of one year for final limit states. It was found that the permissible limit of $10^{-4}$ was satisfied in this structure in L3 and L4 for performance levels of LS and $\mathrm{CP}$, as given in bold in Tab. 3 .

Table 3 The annual reliability indexes of 4 stories $\mathrm{RC}$ frame with systemic approach

\begin{tabular}{|c|c|c|c|c|c|}
\hline \multirow{2}{*}{} & \multicolumn{5}{|c|}{ Performance level : IO } \\
\cline { 2 - 6 } & L0 & L1 & L2 & L3 & L4 \\
\hline$\beta_{\text {an }}$ & 3,217 & 3,094 & 3,220 & 3,534 & 3,592 \\
\hline$P_{\text {an-nsp }}\left(\times 10^{-4}\right)$ & 6,475 & 9,868 & 6,413 & 2,045 & 1,638 \\
\hline \multirow{5}{*}{ Performance level : LS } \\
\cline { 2 - 6 } & L0 & L1 & L2 & L3 & L4 \\
\hline$\beta_{\text {an }}$ & 3,408 & 3,390 & 3,401 & $\mathbf{3 , 8 6 2}$ & $\mathbf{3 , 9 0 5}$ \\
\hline$P_{\text {an-nsp }}\left(\times 10^{-4}\right)$ & 3,267 & 3,496 & 3,360 & $\mathbf{0 , 5 6 1}$ & $\mathbf{0 , 4 7 1}$ \\
\hline & \multicolumn{5}{|c|}{ Performance level : CP } \\
\cline { 2 - 6 } & L0 & L1 & L2 & L3 & L4 \\
\hline$\beta_{\text {an }}$ & 3,470 & 3,455 & 3,461 & $\mathbf{3 , 9 5 1}$ & $\mathbf{4 , 0 0 5}$ \\
\hline$P_{\text {an-nsp }}\left(\times 10^{-4}\right)$ & 2,600 & 2,752 & 2,688 & $\mathbf{0 , 3 8 8}$ & $\mathbf{0 , 3 1 0}$ \\
\hline
\end{tabular}

Also, seismic performance reliability in the structure was evaluated through overall approach which was conducted based on a LSF, defined using overall conducted based on a LSF, defined using overall parameters of the structural response such as maximum interstory drift. In the overall approach, LSFs relating to performance levels of IO, LS and CP are defined as:

$G_{I O-D R}(X)=R P_{D R}(0,01 ; 0,1)-R P_{D R}(X)$

$G_{L S-D R}(X)=R P_{D R}(0,02 ; 0,1)-R P_{D R}(X)$

$G_{C P-D R}(X)=R P_{D R}(0,04 ; 0,1)-R P_{D R}(X)$

where $R P_{D R}$ is maximum drift of the structure. Threshold values of maximum drift are considered with lognormal distribution and numbers in parenthesis show mean and coefficient of variations for the given performance levels [18]. Performance reliability indices of this structure were calculated for LSFs as Eqs. (22) to (24), and the results are presented in Tab. 4. Results of MCS for these LSFs are also demonstrated in Tab. 4, and it was found that the improved RSM properly evaluated seismic performance reliability of this structure. Annual probability of exceeding the given performance levels was calculated for this structure based on overall approach, and results were shown in Tab. 5. It was found that $P_{a n-n s p}$ in this structure for performance level of $\mathrm{CP}$ is less than the permissible limit.

Because the annual seismic performance reliability was calculated for this structure based on overall and systemic approaches, results of these approaches were compared in Fig. 8. The former demonstrates that $P_{a n-n s p}$ based on overall approach did not exceed the permissible limit for performance level of $\mathrm{CP}$; but, in the systemic approach, this limit was satisfied for LS and CP only in L3 and L4. This comparison clarified that the results obtained from overall approach corresponded to results of the proposed systemic approach in limits between L2 and L3; i.e. a structural component exceeded the given performance levels.

Table 4 The performance reliability of 4 stories RC frame with overall

\begin{tabular}{|c|c|c|c|}
\multicolumn{4}{|c}{ approach } \\
\hline LSF & Analysis & $\beta$ & $P_{\text {nsp }}\left(\times 10^{-2}\right)$ \\
\hline \multirow{2}{*}{$G_{I O-D R}$} & FORM & 1,0458 & 14,78 \\
\cline { 2 - 4 } & MCS $\left(N=5 \times 10^{5}\right)$ & 0,9943 & 16,00 \\
\hline \multirow{2}{*}{$G_{L S-D R}$} & FORM & 1,5968 & 5,516 \\
\cline { 2 - 4 } & $\mathrm{MCS}\left(N=5 \times 10^{5}\right)$ & 1,591 & 5,581 \\
\hline \multirow{2}{*}{$G_{C P-D R}$} & $\mathrm{FORM}$ & 2,1024 & 1,776 \\
\cline { 2 - 4 } & $\mathrm{MCS}\left(N=5 \times 10^{5}\right)$ & 2,1035 & 1,771 \\
\hline
\end{tabular}

Table 5 The annual reliability indexes of 4 story RC frame with overall approach

\begin{tabular}{|c|c|c|}
\hline Performance level & $\beta_{a n}$ & $P_{a n-n s p}\left(\times 10^{-4}\right)$ \\
\hline IO & 3,250 & 5,764 \\
\hline LS & 3,521 & 2,151 \\
\hline CP & $\mathbf{3 , 8 1 1}$ & $\mathbf{0 , 6 9 3}$ \\
\hline
\end{tabular}



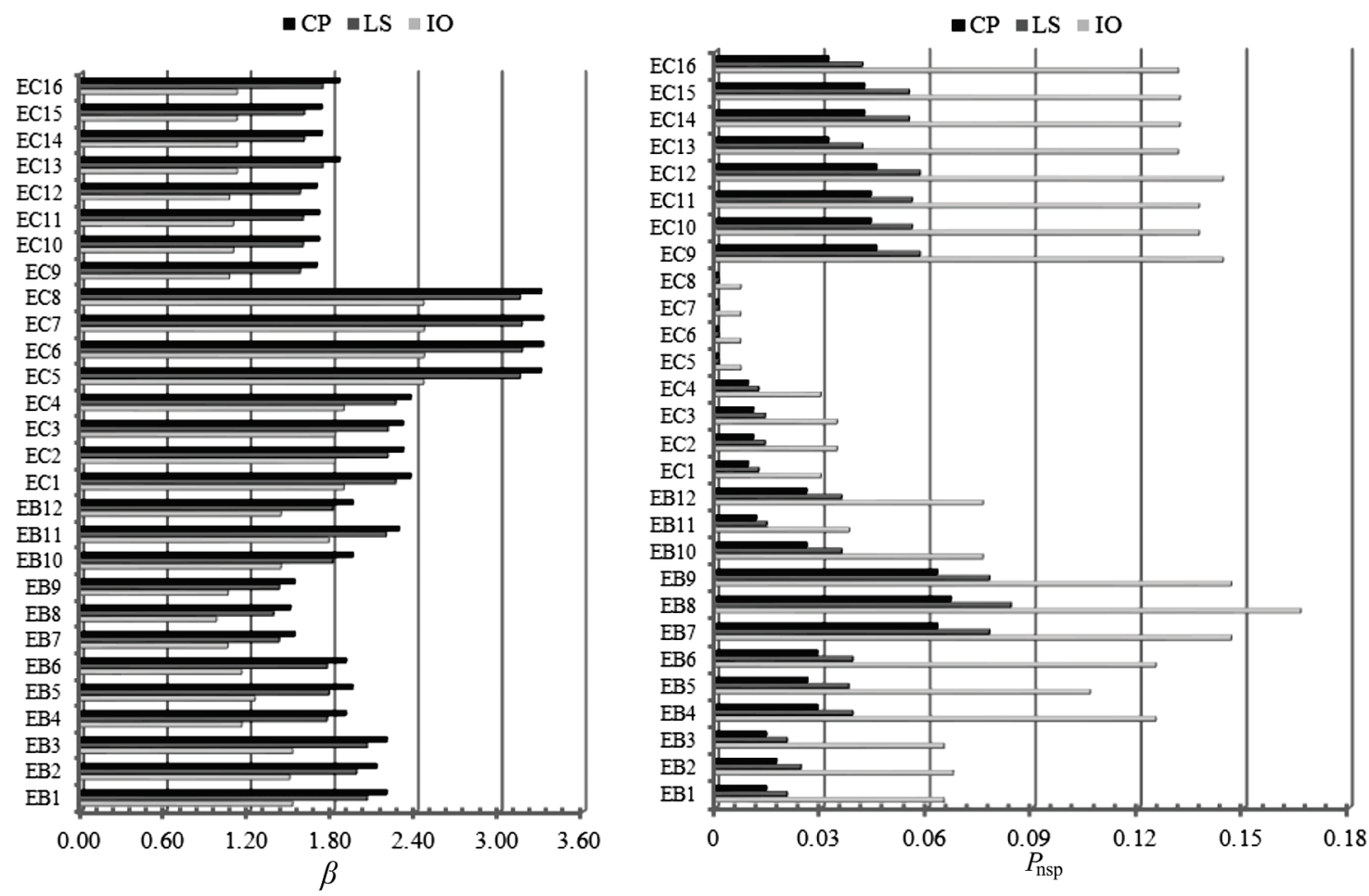

Figure 7 The performance reliability indexes of structural elements and corresponding probabilities for 4 stories RC frame
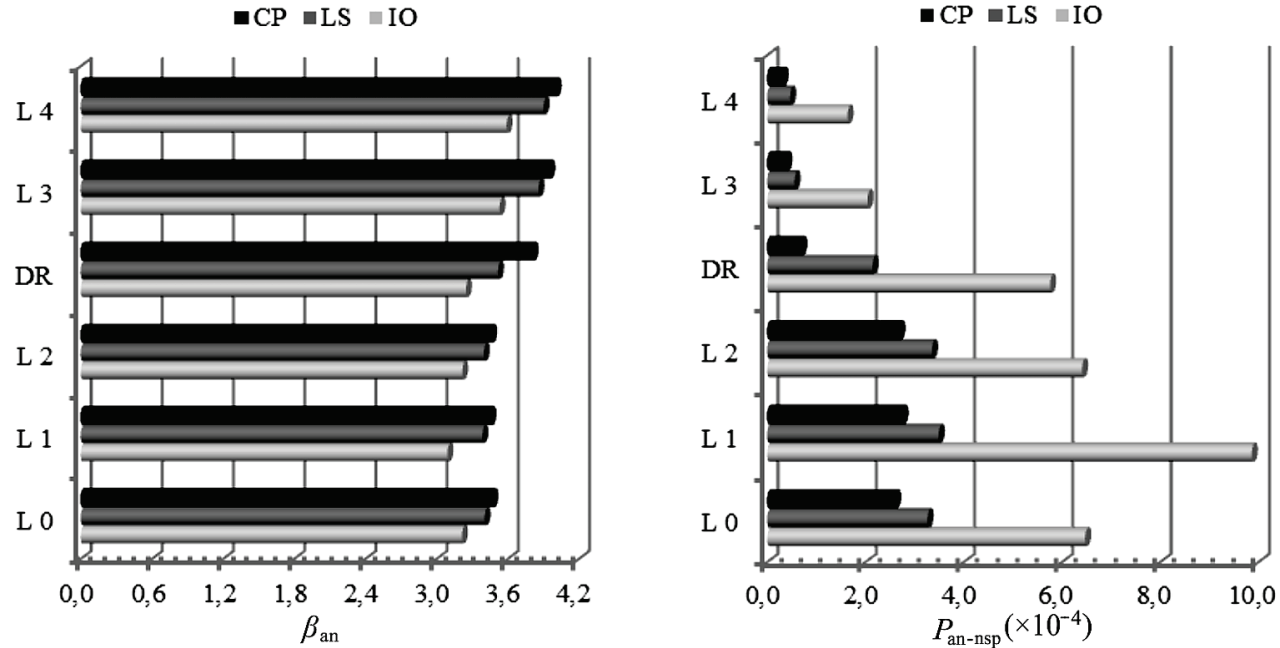

Figure 8 Comparison of the annual performance reliability of RC frame with 4 stories based on overall and systemic approaches

\section{Conclusions}

In this paper, an integrated algorithm was proposed for reliability assessment of the seismic performance of RC structures. This algorithm is based on LSFs at structural components level and a systemic approach for estimating performance reliability of the structure.

The LSFs were estimated using an improved RSM which was accomplished based on an iterative scheme. In this scheme, structural response parameter was calculated by nonlinear dynamical analyses at the experimental points selected in mean range of random variables in the first iteration. The LSF was estimated based on the second-order polynomial with interaction terms of random variables, and FORM was used for calculating performance reliability index as well as relative importance measures of random variables. In the next iterations, sampling center point was updated through a linear interpolation strategy which caused LSF to be properly evaluated in the design point and the experimental points are generated in sampling blocks based on the importance ranking of random variables. The sampling design generates more experimental points for more important random variables; therefore LSF was estimated more properly. Finally, when the tolerance criteria based on coordinates of the sampling center point, design point and quality of RSF were satisfied, the seismic performance reliability of the structural component was calculated using the final fitted RSF and FORM.

Major advantage of the proposed algorithm is that the performance reliability of the RC structure was calculated based on structural components with a systemic approach that employs the most probable non-performance scenario at the components level to establish the series and parallel subsystems. The main advantage of the systemic approach was that variations of parameters relating to properties of materials and loads at structural components level could 
be directly incorporated for analyzing the performance reliability of the structural system. Another advantage of the systemic approach was that the performance reliability of RC structures can be evaluated at different damage levels of the structural components while it was not possible using LSFs based on an overall acceptance criterion of the structure.

The systemic approach was applied for a RC moment structure, in which LSF was defined based on maximum plastic rotation of structural components for the given performance levels. Uncertainties in the material properties, ground motion characteristics and gravity loads were incorporated for estimating the seismic performance of the structure. The performance reliability of the structure was evaluated at different damage levels of the structural components and its results were compared with bound techniques at each analysis level. It was shown that the proposed systemic approach satisfactorily estimated probability of exceeding the given performance levels for different scenarios of the components damage. It was also observed that the probability of exceeding the given performance levels will decrease when the non-performance scenarios are considered at high levels of the components damage.

Overall approach was also used for evaluating seismic performance reliability of this structure, in which LSF was defined based on maximum drift of the structure. This study indicated that the overall approach provided only one reliability index for the seismic performance of the structure, while the proposed systemic method had not such restriction. Results of the systemic approach were compared with overall approach using MCS and improved RSM. This comparison clarified that the overall approach was equivalent to a structural component overpassed the given performance level in the systemic approach.

\section{References}

[1] Guan, X. L.; Melchers, R. E. Effect of Response Surface Parameter Variation on Structural Reliability Estimates. // Structural Safety. 23(2001), pp. 429-444.

[2] Gavin, H. P.; Yau, S. C. High-Order Limit State Functions in the Response Surface Method for Structural Reliability Analysis. // Structural Safety. 30, (2008), pp. 162-179.

[3] Kang, S. C.; Koh, H. M.; Choo, J. F. An Efficient Response Surface Method Using Moving Least Squares Approximation for Structural Reliability Analysis. // Probabilistic Engineering Mechanics. 25, (2010), pp. 365 371.

[4] Buratti, N.; Ferracuti, B.; Savoia, M. Response Surface with Random Factors for Seismic Fragility of Reinforced Concrete Frames. // Structural Safety. 32, (2010), pp. 4251.

[5] Zhao, W.; Qiu, Z. An Efficient Response Surface Method and Its Application to Structural Reliability and Reliability Based Optimization. // Finite Elements in Analysis and Design. 67, (2013), pp. 34-42.

[6] Alibrandi, U. A Response Surface Method for Stochastic Dynamic Analysis. // Reliability Engineering and System Safety. 126, (2014), pp. 44-53.

[7] Jeong, S. H.; Mwafy, A. M.; Elnashai, A. S. Probabilistic Seismic Performance Assessment of Code-Compliant Multi-Story RC Buildings. // Engineering Structures. 34, (2012), pp. 527-537.
[8] Faggella, M.; Barbosa, A.; Conte, J. P.; Spacone, E.; Restrepo, J. I. Probabilistic Seismic Response Analysis of a 3-D Reinforced Concrete Building. // Structural Safety. 44, (2013), pp. 11-27

[9] Kim, S. H.; Na, S. W. Response Surface Method Using Vector Projected Sampling Points. // Structural Safety. 19, (1997), pp. 3-19.

[10] Zheng, Y.; Das, P. K. Improved Response Surface Method and Its Application to Stiffened Plate Reliability Analysis. // Engineering Structures. 22, (2000), pp. 544-551.

[11] Hasofer, A.; Lind, N. Exact and Invariant Second-Moment Code Format. // Engineering Mechanics, ASCE. 100, 1(1974), pp. 111-121.

[12] Engineering Design Reliability Handbook. // First- and Second-Order Reliability Methods / Der Kiureghian,A. USA: CRC Press LLC, (2004), pp. 303-326.

[13] Huh, J.; Haldar, A. Seismic Reliability of Nonlinear Frames With PR Connections Using Systematic RSM. // Probabilistic Engineering Mechanics. 17, (2002), pp. 177 190.

[14] Nguyen, X. S.; Sellier, A.; Duprat, F.; Pons, G. Adaptive Response Surface Method Based on a Double Weighted Regression Technique. // Probabilistic Engineering Mechanics. 24, (2009), pp. 135-143.

[15] Hohenbichler, M.; Rackwitz, R. First-Order Concepts in System Reliability. // Structural Safety. 1, 3(1983), pp. 177-188

[16] Thoft-Christensen, P.; Sørensen, J.D. Reliability Analysis of Elasto-Plastic Structures. // Proc. 11. IFIPConf. System Modeling and Optimization / Copenhagen, 1984, pp. 556566

[17] Gollwitzer, S.; Rackwitz, R. Equivalent Components in First-Order System Reliability. // ReliabilityEngineering. 5, (1983), pp. 99-115.

[18] Federal Emergency Management Agency FEMA-356. Prestandard and Commentary for Seismic Rehabilitation of Buildings. // Building Seismic Safety Council Washington DC, 2000

[19] Applied Technology Council ATC-40. Seismic Evaluation and Retrofit of Concrete Buildings. // California Seismic Safety Commission, 1996.

[20] Khademi, M. H. Study on Scaling of Spectral Quantities of Iranian Accelerograms through Magnitude and Geological Distance of the Site. // Building and Housing Research Center: No. R-376, 2004.

[21] Sabetta, F.; Pugliese, A.Estimation of Response Spectra and Simulation of Non-Stationary Earthquake Ground Motions. // Bulletin of the Seismological Society of America. 86, 2(1996), pp. 337-352.

[22] Iranian Loading Code. National Building Regulations: Volume 6. Building and Housing Research Center, 2009.

[23] Nowak, A. S.; Collins, K. R. Reliability of Structures. McGraw-Hill,2000

[24] Valles, R. E.; Reinhorn, A. M.; Kunnath, S. K.; Li, C.; Madan, A. IDARC 2D Version 6.1: AComputer program for Inelastic Damage Analysis of Buildings. // Technical Report NCEER-96-0010, StateUniversity of New York at Buffalo, 2005.

[25] Design and Construction of Reinforced Concrete Structures Code. National Building Regulations: Volume 9, Building and Housing Research Center, 2009.

[26] SAKO. Probabilistic Calibration of Partial Safety Factors in the Euro codes, 1999.

[27] Ellingwood, B.; Galambos, T. V.; MacGregor, J. G.; Cornell, C.A. Development of a Probability Based Load Criterion for American National Standard A58: Building Code Requirements for Minimum Design Loads in Buildings and Other Structures. // National Bureau of Standards SpecialPub.No. 577, Washington D. C., 1980. 
[28] Song, J.; Der Kiureghian, A. Bounds on Systems Reliability by Linear Programming. // Engineering Mechanics. 129, 6(2003), pp. 627-636.

[29] Moller, O.; Foschi, R. O.; Quiroz, L. M., Rubinstein M. Structural Optimization for Performance-Based Design in Earthquake Engineering: Applications of Neural Networks. // Struct Safety. 31, (2009), pp. 490-499.

[30] NKB. Recommendation for Loading- and Safety Regulations for Structural Design. NKB-Report No. 36, 1978.

[31] JCSS: Probabilistic model code for reliability based design. The Joint Committee on Structural Safety, 2001.

\section{Authors' addresses}

\section{Hossein Shahraki}

University of Sistan and Baluchestan

Department of Civil Engineering, Faculty of Engineering,

P.O. Box 98164-161, Zahedan, Iran

E-mail: Shahraki.h@hotmail.com

\section{Naser Shabakhty}

University of Sistan and Baluchestan

Department of Civil Engineering, Faculty of Engineering,

P.O. Box 98164-161, Zahedan, Iran

E-mail: Shabakhty@eng.usb.ac.ir

Tel. /Fax: +98 5412447092 